\title{
Probiotic Therapy for the Treatment of Spondyloarthritis: A Randomized Controlled Trial
}

\author{
KATHERINE JENKS, SIMON STEBBINGS, JEREMY BURTON, MICHAEL SCHULTZ, PETER HERBISON, \\ and JOHN HIGHTON
}

ABSTRACT. Objective. To investigate the effect of an orally administered probiotic on disease activity, fatigue, quality of life, and intestinal symptoms in patients with active spondyloarthritis.

Methods. Patients with active spondyloarthritis [defined as Bath Ankylosing Spondylitis Disease Activity Index (BASDAI) $\geq 3$, Bath Ankylosing Spondylitis Functional Index (BASFI) $\geq 3$, Maastricht Ankylosing Spondylitis Enthesitis Score (MASES) $\geq 2$, or peripheral joint count $\geq 2$ ] were randomized to oral probiotic or placebo for 12 weeks. Patients and assessors were blinded to treatment allocation. The primary outcome measure was $10 \%$ improvement in the BASFI. Additional outcome measures were improvements in the ASsessments in Ankylosing Spondylitis (ASAS)-endorsed core domains: pain, spinal mobility, patient global, peripheral joint and entheseal scores, stiffness, C-reactive protein, and fatigue. The ASAS20 criteria, a composite measure of response, were also applied. Quality of life and bowel symptoms were quantified using the Ankylosing Spondylitis Quality of Life Questionnaire (ASQoL) and Dudley Inflammatory Bowel Symptom Questionnaire (DISQ).

Results. Sixty-three patients were randomized to oral probiotic $(n=32)$ or placebo $(n=31)$. All patients completed the trial. No significant difference was noted between groups in any of the core domains. The mean BASFI fell from $3.5 \pm 2.0$ to $2.9 \pm 1.9$ in the probiotic group and from $3.6 \pm 1.9$ to $3.1 \pm 2.2$ in the placebo group $(\mathrm{p}=0.839)$. The mean BASDAI fell from $4.2 \pm 2.2$ to $3.2 \pm 2.1$ in the probiotic group and $4.5 \pm 2.0$ to $3.9 \pm 2.2$ in the placebo group $(\mathrm{p}=0.182)$. No significant adverse events were recorded in the probiotic-treated group.

Conclusion. In this randomized controlled trial, the probiotic combination administered did not demonstrate significant benefit over placebo, despite a theoretical rationale for this therapy. (First Release August 15 2010; J Rheumatol 2010;37:2118-25; doi:10.3899/jrheum.100193)

Key Indexing Terms:

SPONDYLOARTHRITIS

INTESTINAL INFLAMMATION
PROBIOTICS

QUALITY OF LIFE
DISEASE ACTIVITY

BOWEL SYMPTOMS
Spondyloarthritis ( $\mathrm{SpA})$ is associated with significant disability and adversely affects quality of life ${ }^{1}$. It affects individuals during their most economically productive years. Until recently, with the advent of biologic therapies, effective treatment of spinal disease in $\mathrm{SpA}$ was limited to nonsteroidal antiinflammatory drugs (NSAID) and physical

From the Department of Medicine, University of Otago School of Medicine, Dunedin; BLIS Technologies Ltd., Dunedin; and Department of Preventive and Social Medicine, University of Otago School of Medicine, Dunedin, New Zealand.

Supported by Arthritis New Zealand and the Tony Hocken Research Scholarship, University of Otago.

K. Jenks, MBChB, MMedSc, FRACP; S. Stebbings, MBBS, MMedSci, FRACP, Senior Lecturer, Department of Medicine, University of Otago School of Medicine; J. Burton, PhD, BLIS Technologies Ltd.; M. Schultz, $M D, P h D, F R A C P$, Department of Medicine; P. Herbison, MSc,

Department of Preventive and Social Medicine; J. Highton, MD, FRACP, Professor, Department of Medicine, University of Otago School of Medicine.

Address correspondence to Dr. K. Jenks, Department of Medicine, Dunedin School of Medicine, University of Otago, PO Box 913, Dunedin 9054, New Zealand.E-mail: kateymeuli@hotmail.com

Accepted for publication May 6, 2010. therapy ${ }^{2}$. The efficacy of disease-modifying drugs with proven benefits in rheumatoid arthritis (RA) such as methotrexate (MTX) and sulfasalazine have been disappointing in $\mathrm{SpA}^{3,4}$. While effective in $\mathrm{SpA}$, the high cost of biologic therapy, together with an associated risk of serious infection such as tuberculosis, means that investigation of cheaper and safer alternative therapies is still important ${ }^{5}$. Probiotics have been suggested as one such potential therapy ${ }^{6}$.

Probiotics are defined by the World Health Organization as "Live microorganisms, which when administered in adequate amounts, confer a health benefit on the host" are widely available without prescription. It is estimated that each year over 20 billion doses of probiotics are sold ${ }^{8}$. Proposed beneficial effects include modulation of intestinal microbiota, strengthening of the epithelial barrier, and immunomodulation ${ }^{9}$. Probiotics have been shown both in vitro and in vivo to reduce mucosal inflammation via modulation of cytokine levels and other inflammatory mediators. In interleukin 10 (IL-10) knockout mice and inflammatory bowel disease (IBD) patients with pouchitis, administration

Personal non-commercial use only. The Journal of Rheumatology Copyright (c) 2010. All rights reserved. 
of probiotics has resulted in stimulation of antiinflammatory cytokines (IL-10, transforming growth factor $\beta$ ) and suppression of proinflammatory cytokines (tumor necrosis factor- $\alpha$; TNF- $\alpha)^{10,11}$. Evidence of a clinical benefit in patients with IBD has come from studies of probiotics in the prevention of pouchitis and maintenance of remission in ulcerative colitis ${ }^{12,13}$. Improvement in abnormal intestinal permeability in patients with IBD has also been demonstrated following probiotic therapy ${ }^{14}$. There is evidence that multistrain and multispecies probiotic preparations are superior to preparations containing a single probiotic strain, particularly if the strains used are synergistic ${ }^{15}$. It should also be noted that evidence for potential harm from the use of probiotics has come from studies in patients with pancreatitis and immunosuppression ${ }^{16,17}$.

A rationale for probiotics as a potential treatment in SpA lies both in the presence of ileocolitis in $\mathrm{SpA}^{18}$ and demonstration of a potential role for the enteric microflora in the development of $\mathrm{SpA}^{19}$. Evidence of intestinal inflammation in patients with SpA comes from ileocolonoscopy showing both macroscopic and histologic changes resembling $\mathrm{IBD}^{18}$. In addition, fecal calprotectin, a noninvasive measure of intestinal inflammation, is elevated in patients with SpA and their relatives ${ }^{20}$. While ileocolitis in patients with SpA has been described as asymptomatic, we have shown that patients with active SpA have bowel symptoms similar in severity to patients with Crohn's disease ${ }^{21}$. Although the intestinal bacterial profile in patients with $\mathrm{SpA}$ is similar to that of controls ${ }^{22}$, individuals with SpA exhibit a loss of tolerance to their autochthonous microbiota. For example, patients with ankylosing spondylitis (AS) produced significantly less IL-10 than controls on exposure to autologous bacteroides species ${ }^{23}$. Increased intestinal permeability has also been demonstrated in patients with SpA compared to healthy controls ${ }^{24}$. A suggested link between gut inflammation and the pathogenesis of SpA involves an increase in intestinal permeability allowing luminal antigens or bacteria to interact with the host immune system more readily ${ }^{25}$. A dysfunctional immune response to these antigens may result in development and chronicity of $\mathrm{SpA}^{23}$.

We hypothesized that administration of an oral probiotic may reduce intestinal inflammation in individuals with $\mathrm{SpA}$ with a consequent clinical improvement in disease activity, well-being, and intestinal symptoms. The objective of our study was to investigate the efficacy and safety of an orally administered probiotic in patients with active SpA over a period of 12 weeks.

\section{MATERIALS AND METHODS}

Patients. Patients meeting the European Spondylarthropathy Study Group (ESSG) criteria for SpA were recruited from a database in the Department of Rheumatology, Dunedin Hospital, New Zealand ${ }^{26}$. Only patients with active disease as defined by Bath Ankylosing Spondylitis Disease Activity Index $($ BASDAI) $\geq 3$, Bath Ankylosing Spondylitis Functional Index (BASFI) $\geq 3$, Maastricht Ankylosing Spondylitis Enthesitis Score (MASES) $\geq 2$, or peripheral joint count $\geq 2$ were included in the trial ${ }^{27,28,29}$.
Patients were excluded if they were pregnant, under 18 years of age, had a diagnosis of IBD, severe immunosuppression, or current gastrointestinal infection. Participants received their usual medication, including treatment with NSAID, oral or intraarticular steroids, and disease-modifying antirheumatic drugs (DMARD). Details of treatment with these therapies were recorded. Participants were advised not to take yogurt or any probiotic-containing preparation for the duration of the trial.

Clinical assessments were undertaken in the outpatient clinic at Weeks $0,4,8,12$, and 16 by a single assessor. Both patients and assessor were blinded to the treatment received. The following baseline data were recorded: age, sex, ethnicity, diagnosis, disease duration, comorbidities, and history of uveitis or psoriasis. Medications and doses were recorded at each visit. The ASsessments in Ankylosing Spondylitis International Working Group (ASAS) endorsed core set of domains and appropriate measurement tools for their assessment were employed ${ }^{30}$. Function was measured using the BASFI, consisting of 10 questions relating to daily activities, such as putting on socks and climbing stairs. Each activity is rated on a $100-\mathrm{mm}$ visual analog scale (VAS) and a total score divided by 10 (giving a range $0-10)^{28}$. The BASDAI was used as a measure of disease activity, with 6 questions about fatigue, spinal pain, peripheral arthritis, enthesitis, and morning stiffness (range $0-10)^{27}$. Patient global and pain assessments were recorded on a 10-cm VAS. For the global assessment, patients were asked, "Considering all the ways in which illness and health conditions may affect you, please mark on the line below to show how well you are doing," with the anchors being "very well" and "very poorly." The statement for the pain assessment "please mark the line at the point which best represents your level of pain today" was accompanied by the anchors "no pain" and "pain as bad as it could be." For both scales a higher score (range 0-10) indicates poorer well-being and higher level of pain, respectively.

In addition, intensity of fatigue was measured using the Multidimensional Assessment of Fatigue (MAF) scale, expressed as the total Global Fatigue Index (GFI). The MAF-GFI scale contains 16 items measuring 4 dimensions of fatigue: severity, distress, degree of interference with activities of daily living, and timing. MAF-GFI scores range from 1 (no fatigue) to 50 (severe fatigue) ${ }^{31}$. This scale has been demonstrated to have a strong correlation with both disease activity and functional impairment in patients with $\mathrm{AS}^{32}$. Convergent validity has been reported with correlation coefficients of $0.692(\mathrm{p}<0.001)$ and $0.712(\mathrm{p}<0.001)$ for the BASDAI and BASFI, respectively ${ }^{32}$. The Ankylosing Spondylitis Quality of Life Questionnaire (ASQoL), measuring self-perceived severity of disease, current flare of symptoms, and general health was also administered $^{33}$. The ASQoL contains 18 items concerning the influence of disease from the patient's perspective. For each statement the patient responds "yes" or "no." The total score ranges from 0 (good QoL) to 18 (poor QoL). The ASQoL has demonstrated both reproducibility and construct validity and correlates highly with both the BASFI and BASDAI in AS patients. Bowel symptoms were assessed using the Dudley Inflammatory Bowel Symptom Questionnaire (DISQ). Developed to assess bowel symptoms in patients with IBD, it has shown validity in quantifying bowel symptoms in patients with $\mathrm{AS}^{21}$. Physician's global assessment on a 100-mm VAS was also recorded.

Physical examination included peripheral joint count and MASES index ${ }^{29}$. Peripheral joint inflammation was assessed according to the $66 / 68$ joint count. For this measure, swelling or tenderness of individual joints is assessed and recorded to give a total score out of 66 (swollen) or 68 (tender joints). The hip joints are excluded from the swollen joint count. The MASES involves palpation of 13 entheseal regions: first and seventh costochondral joints, posterior and anterior superior iliac spines, iliac crests, fifth lumbar spinous process, and proximal insertion of the Achilles tendons. The regions are scored as tender or nontender with a final score ranging from 0 to 13

Spinal and hip mobility was assessed using the Bath Ankylosing Spondylitis Metrology Index ${ }^{34}$, which includes measures of cervical spine rotation, tragus to wall distance, lumbar side flexion, lumbar flexion (modified Schobers), and intermalleolar distance. Scores range from 0 to 10 , a

Personal non-commercial use only. The Journal of Rheumatology Copyright (c) 2010. All rights reserved. 
higher score indicating greater limitation of movement. Skin and nails were examined for evidence of psoriasis, and presence or absence of sacroiliac joint tenderness on direct palpation was noted. Chest expansion was measured at the level of the fourth intercostal space in centimeters. Body mass index was recorded. Radiographs of the sacroiliac joints were reviewed by a radiologist for the presence of sacroiliitis.

C-reactive protein (CRP; mg/l) was measured at Weeks 0, 4, 12, and 16. A subgroup of 31 patients provided fecal samples at Weeks 0,12 , and 16 . Calprotectin measurements as a marker of intestinal inflammation were performed on all fecal samples by ELISA. Calprotectin, a calcium-binding protein, is present in all body fluids in proportion to the degree of inflammation present ${ }^{35}$. It has proven to be a useful biomarker of intestinal inflammation and can be easily quantified in a single fecal sample using ELISA $^{35}$; measurements are given in $\mathrm{mg} / \mathrm{kg}$. Among control populations, median values for fecal calprotectin range from 10 to $35 \mathrm{mg} / \mathrm{kg}^{36,37}$. Elevated values in excess of $50-150 \mathrm{mg} / \mathrm{kg}$ have been suggested as identifying patients with potential $\mathrm{IBD}^{38}$.

Random block number generation by BLIS Technologies (Dunedin, New Zealand) was used for randomization and sequentially numbered containers ensured allocation concealment. This external treatment allocation enabled patient randomization with blinding of both patients and assessors. Patients and assessors remained unaware of allocation throughout the trial. The study drug was identified by the assessors as a random number sequence, to allow documentation of treatment. The allocation code was broken only at completion of the data entry process to enable statistical analysis.

Study treatment. The probiotic preparation contained 3 strains of bacteria, which contributed $5.5 \%$ of the weight of the powder composition. The remainder of the formulation consisted of the excipient ingredients, identical to placebo. The strains used in the active treatment were Streptococcus salivarius K12 (1 x $\left.10^{8} \mathrm{cfu} / \mathrm{g}\right)$, Bifidobacterium lactis LAFTI B94 (4 x 10 $\mathrm{cfu} / \mathrm{g})$, and Lactobacillus acidophilus LAFTI L10 (4 x $\left.10^{8} \mathrm{cfu} / \mathrm{g}\right)$. The placebo consisted of glucidex $37.6 \%$, trehalose $56.49 \%$, and vanilla flavor $0.43 \%$ and was identical in appearance, taste, and texture to the active probiotic treatment. Both probiotic and placebo were formulated by BLIS Technologies. BLIS Technologies had no involvement in study funding, study design, patient assessment, or statistical analysis. Participants were provided with a small plastic spoon and instructed to take one level spoonful (approximately $0.8 \mathrm{~g}$ ) by mouth twice daily for 12 weeks. They were advised to keep the study drug in a cool dark place, but not necessarily to refrigerate. At baseline, Week 4, and Week 8 patients were given a fresh supply of probiotic or placebo and any remaining study drug from the preceding 4 weeks was collected to monitor compliance.

Outcome measures. The primary outcome measure was an improvement from baseline in physical function as measured by BASFI. Additional outcome measures included improvement from baseline of individual domains: disease activity according to BASDAI, pain VAS, patient global VAS, fatigue according to MAF, bowel symptoms measured by DISQ, quality of life according to ASQoL, peripheral joint count, MASES index, and CRP. The ASAS20 criteria were also applied at Week $12^{39}$. This is a composite measure of disease activity in AS, validated as a measure of short-term improvement. To meet the ASAS20 criteria the patient must have an improvement of $\geq 20 \%$ and absolute improvement of $\geq 10$ units (on a scale of $0-100$ ) in $\geq 3$ of 4 domains, including patient global assessment (100-mm VAS), pain (100-mm VAS), function (BASFI score), and inflammation as represented by the mean of the 2 morning stiffness-related BASDAI VAS scores. There must also be absence of deterioration in the potential fourth domain, deterioration defined as a change for the worse of $\geq 20 \%$ and $\geq 10$ units (on a scale of 0-100).

Statistical analysis. Previous studies using the BASFI have reported a baseline mean (standard deviation) of $4.2(2.9)^{40}$. We considered a $10 \%$ change in the mean BASFI to be an important change and designed the study to have $80 \%$ power. For this level of change it was determined that a minimum of 29 participants would be required for each group. The results were analyzed using ANCOVA, with baseline values as covariates.
Ethical approval for the study was obtained from the Lower South Regional Ethics Committee. All subjects were over 18 years of age and gave written informed consent, in accord with the Declaration of Helsinki.

\section{RESULTS}

Participants. In total, 63 patients were randomized to treatment with probiotic $(n=32)$ or placebo $(n=31)$ (Figure 1). All 63 patients completed the 12-week trial. Table 1 shows baseline characteristics of the 2 groups. There were no differences between the groups at baseline. The mean age of participants was 43.3 years (range 19-76) and the majority of patients were male $(63 \%)$. Mean disease duration was 8.9 years (range 1-53), with $57 / 63$ patients $(90.5 \%)$ positive for HLA-B27. The majority of patients $(81.0 \%)$ had a diagnosis of AS, the remainder having undifferentiated SpA (17.5\%) and psoriatic SpA (1.6\%). A history of current or previous anterior uveitis was present in $19(30.2 \%)$ and a history of psoriasis in 5 (7.9\%). At baseline 48/63 (76.2\%) patients were receiving concomitant treatment with NSAID and 2/63 were taking oral glucocorticoids. 3/63 patients had at least one intraarticular steroid injection within the 3 months prior to the trial, 1 in the placebo group and 2 in the probiotic group. Joints injected included ankle, knee, elbow, and metatarsophalangeal joints. 18/63 (28.6\%) were prescribed DMARD, $8 / 32(25.0 \%)$ in the probiotic and 10/31 (31.3\%) in the placebo group (Table 2). Thirty-one participants provided fecal samples at baseline. Fecal calprotectin concentration was increased at baseline, with a median concentration of $96 \mathrm{mg} / \mathrm{kg}$ (range $29-1194 \mathrm{mg} / \mathrm{kg}$ ). There was no significant difference between probiotic $(174 \mathrm{mg} / \mathrm{kg})$ and placebo groups $(190 \mathrm{mg} / \mathrm{kg})$ at baseline $(\mathrm{p}=0.79)$. Measures of disease activity and function were similar between active and placebo groups at baseline (Table 3).

Compliance. Participants returned all study drug containers at Weeks 4, 8, and 12. Containers were weighed to document compliance. Over the 12 -week trial participants were instructed to take a total of $134 \mathrm{~g}$ of the treatment powder. In the probiotic group the mean amount taken was $124 \mathrm{~g}$ and in the placebo group $122 \mathrm{~g}$, indicating excellent compliance. Efficacy. The following outcome measures showed improvement over the 12-week trial in both groups, with no statistically significant difference between probiotic and placebo (Table 3). The mean BASFI fell from 3.5 (SD 2.0) to 2.9 (SD 1.9) in the probiotic group and from 3.6 (SD 1.9) to 3.1 (SD 2.2) in the placebo group ( $\mathrm{p}=0.839)$. The mean BASDAI dropped from 4.2 (SD 2.2) to 3.2 (SD 2.1) in the probiotic group and 4.5 (SD 2.0) to 3.9 (SD 2.2) in the placebo group $(\mathrm{p}=0.182)$. Bowel symptoms as measured by the DISQ improved in both groups over the 12-week trial, with mean scores falling from 8.2 (SD 4.7) to 6.6 (SD 5.1) in the probiotic group and 10.1 (SD 6.7) to 8.8 (SD 8.0) in the placebo group $(\mathrm{p}=0.442)$. The following indicators showed improvement in both groups during the study: pain VAS, patient global VAS, MAF, ASQoL, and physician

Personal non-commercial use only. The Journal of Rheumatology Copyright (c) 2010. All rights reserved. 


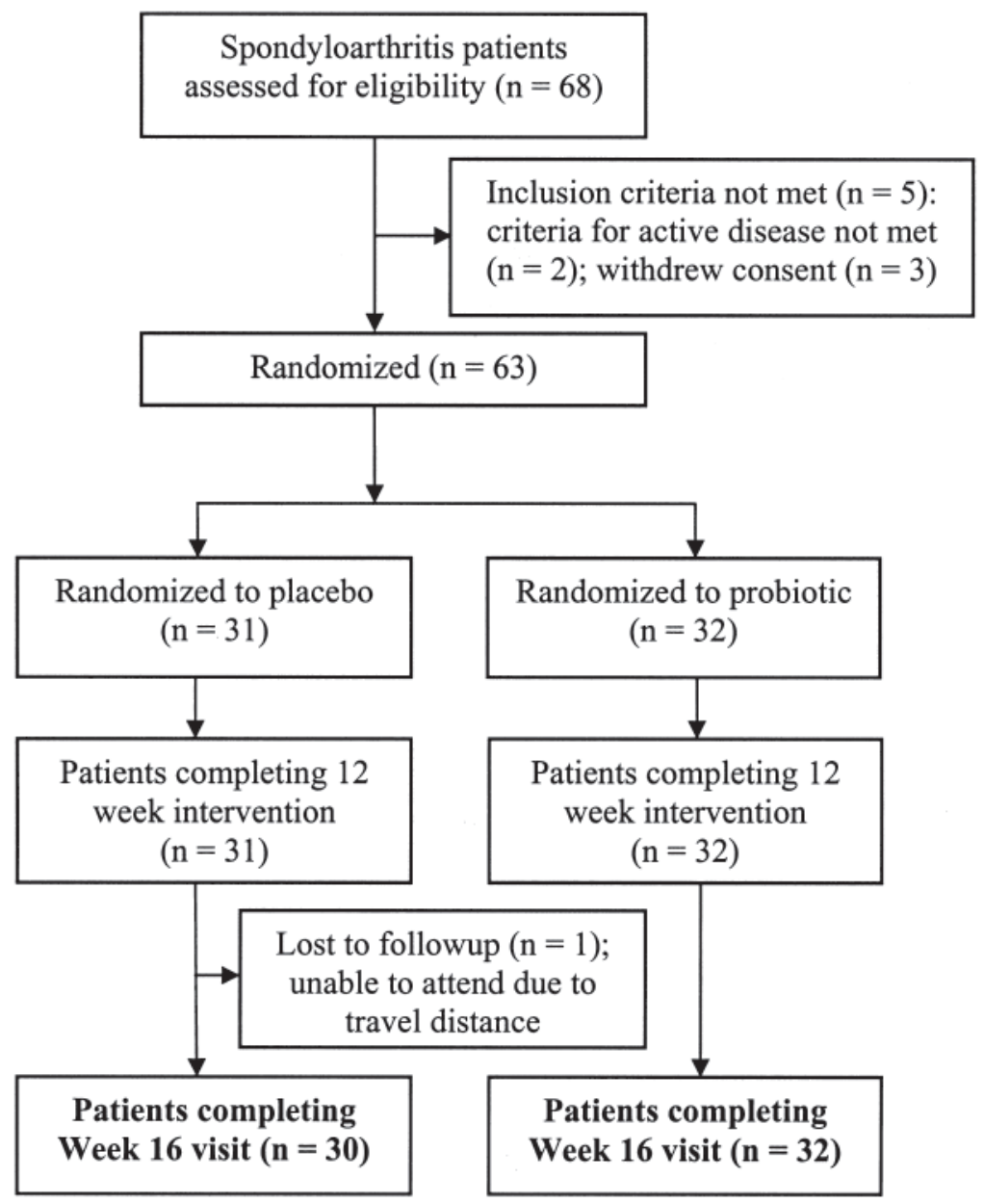

Figure 1. The trial profile.

Table 1. Baseline characteristics of participants.

\begin{tabular}{lcc}
\hline Characteristic & Probiotic, $\mathrm{n}=32$ & Placebo, $\mathrm{n}=31$ \\
\hline Male (\%) & $19(59)$ & $21(68)$ \\
Mean (SD) age, yrs & $45.5(15)$ & $41.1(10)$ \\
Mean (SD) disease duration, yrs & $9.8(13)$ & $7.9(7)$ \\
HLA-B27-positive (\%) & $30(94)$ & $27(87)$ \\
Diagnosis (\%) & & \\
Ankylosing spondylitis & $27(84)$ & $24(77)$ \\
Psoriatic arthritis & $1(3)$ & 0 \\
Undifferentiated spondyloarthritis & $4(13)$ & $7(23)$ \\
History of anterior uveitis (\%) & $9(28)$ & $10(32)$ \\
History of psoriasis (\%) & $4(13)$ & $1(3)$ \\
\hline
\end{tabular}

global assessment, but none of these changes were statistically significant.

Applying the ASAS20 criteria, a response was observed in the minority of participants with no statistically significant difference between active and placebo groups. At Week 4 an ASAS20 was achieved by $1 / 32$ in the probiotic group and $1 / 31$ in the placebo group $(p=0.982)$. At Week 12,6/32
Table 2. Concomitant treatment at baseline.

\begin{tabular}{lcc}
\hline Treatment & Probiotic, $\mathrm{n}=32$ & Placebo, $\mathrm{n}=31$ \\
\hline NSAID (\%) & $24(75)$ & $24(77)$ \\
Oral glucocorticoids (\%) & 0 & $2(7)$ \\
Intraarticular glucocorticoids (\%) & $2(6)$ & $1(3)$ \\
DMARD (\%) & $8(25)$ & $10(31)$ \\
Sulfasalazine (\%) & $6(19)$ & $7(23)$ \\
Methotrexate (\%) & $2(6)$ & $3(10)$ \\
\hline
\end{tabular}

NSAID: nonsteroidal antiinflammatory drugs: DMARD: disease-modifying antirheumatic drugs.

$(18.8 \%)$ in the probiotic and $9 / 31(25.8 \%)$ in the placebo group met ASAS criteria for a $20 \%$ improvement $(\mathrm{p}=$ $0.338)$.

At Week 12 the median calprotectin concentrations were essentially unchanged (probiotic group $173 \mathrm{mg} / \mathrm{kg}$, placebo $177 \mathrm{mg} / \mathrm{kg}$ ) with no significant probiotic effect.

Adverse events. A total of 26 patients reported adverse events, $14 / 32(43.8 \%)$ in the probiotic group and 12/31 $(38.7 \%)$ of those taking placebo (Table 4$)$. There were no 
Table 3. Individual measures of disease activity at Week 12.

\begin{tabular}{|c|c|c|c|c|c|}
\hline & \multicolumn{2}{|c|}{$\begin{array}{l}\text { Probiotic, } \\
\mathrm{n}=32\end{array}$} & \multicolumn{2}{|c|}{$\begin{array}{c}\text { Placebo, } \\
\mathrm{n}=31\end{array}$} & \multirow[t]{2}{*}{ Probiotic Effect $(95 \% \mathrm{CI})$} \\
\hline & $\begin{array}{l}\text { Baseline, } \\
\text { mean (SD) }\end{array}$ & $\begin{array}{l}\text { Week } 12 \text {, } \\
\text { mean }(\mathrm{SD})\end{array}$ & $\begin{array}{l}\text { Baseline, } \\
\text { mean (SD) }\end{array}$ & $\begin{array}{l}\text { Week } 12 \text {, } \\
\text { mean }(\mathrm{SD})\end{array}$ & \\
\hline BASFI & $3.5(2.0)$ & $2.9(1.9)$ & $3.6(1.9)$ & $3.1(2.2)$ & $-0.1(-0.7-0.6)$ \\
\hline BASDAI & $4.2(2.2)$ & $3.2(2.1)$ & $4.5(2.0)$ & $3.9(2.2)$ & $-0.6(-1.6-0.3)$ \\
\hline Patient global VAS & $3.4(2.2)$ & $2.7(2.0)$ & $4.0(2.4)$ & $3.3(2.4)$ & $-0.4(-1.4-0.7)$ \\
\hline Swollen joint count & $0.4(0.9)$ & $0.25(0.9)$ & $0.5(1.1)$ & $0.2(0.5)$ & $0.1(-0.2-0.4)$ \\
\hline MASES & $3.5(2.7)$ & $2.3(3.0)$ & $3.8(2.9)$ & $2.9(3.2)$ & $-0.4(-1.5-0.6)$ \\
\hline BASMI & $2.7(2.6)$ & $2.3(2.3)$ & $2.7(3.0)$ & $2.4(3.0)$ & $-0.01(-0.6-0.6)$ \\
\hline CRP & $6.8(6.7)$ & $6.7(6.3)$ & $10.0(11.3)$ & $11.3(11.2)$ & $-3.5(-7.8-0.8)$ \\
\hline ASQoL & $6.9(4.5)$ & $4.9(4.8)$ & $6.4(4.3)$ & $5(4.7)$ & $-0.5(-2.0-1.1)$ \\
\hline MAF & $24.3(11.7)$ & $21.9(10.2)$ & $25.8(11.4)$ & $23.9(11.1)$ & $-1.2(-5.9-3.4)$ \\
\hline
\end{tabular}

BASFI: Bath AS Functional Index; BASDAI: Bath AS Disease Activity Index; VAS: visual analog scale; MASES: Maastrict AS Enthesitis Score; BASMI: Bath AS Metrology Index; CRP: C-reactive protein; ASQoL: AS Quality of Life questionnaire; MAF: Multidimensional Assessment of Fatigue; DISQ: Dudley Inflammatory Bowel Symptom Questionnaire.

Table 4. Adverse events.

\begin{tabular}{lcc}
\hline & $\begin{array}{c}\text { Probiotic, } \\
\mathrm{n}=32\end{array}$ & $\begin{array}{c}\text { Placebo, } \\
\mathrm{n}=31\end{array}$ \\
\hline Any adverse event (\%) & $14(43.8)$ & $12(38.7)$ \\
Serious adverse event & 0 & 0 \\
Change in bowel habit & 7 & 6 \\
Increased flatus & 2 & 3 \\
Nausea & 4 & 1 \\
Abdominal pain & 2 & 1 \\
Flu-like illness & 1 & 2 \\
Headache & 1 & 1 \\
Diarrhea and vomiting & 1 & 1 \\
Cold/upper respiratory tract infection & 1 & 0 \\
Bloating & 0 & 1 \\
Reflux & 1 & 0 \\
Vertigo & 0 & 1 \\
\hline
\end{tabular}

serious adverse events reported and none required discontinuation of the study drug. The most common adverse event was a change in bowel habit, reported by 7 of those in the probiotic group and 6 in the placebo group. In the probiotic group there were also reports of nausea (4), increased flatus (2), abdominal pain (2), flu-like illness (1), headache (1), diarrhea and vomiting (1), upper respiratory tract infection (1), and gastroesophageal reflux (1). In the placebo group there were reports of increased flatus (3), flu-like illness (2), nausea (1), abdominal pain (1), headache (1), diarrhea and vomiting (1), bloating (1), and vertigo (1).

While nausea was reported by $4(12.5 \%)$ patients in the probiotic group and only 1 in the placebo group, this was not a statistically significant difference $(\mathrm{p}=0.173)$. Of those reporting nausea in the probiotic group, 2 patients were taking sulfasalazine and had resolution of their symptoms with a reduction in sulfasalazine dose. A third patient, taking metho- trexate, had spontaneous resolution of nausea, as did the fourth patient, who was not receiving DMARD therapy. The patient reporting nausea in the placebo group was not taking DMARD and also had spontaneous resolution of symptoms.

\section{DISCUSSION}

Our study aimed to determine whether probiotics are an effective and safe therapy for spondyloarthritis. It is the first randomized double-blind placebo-controlled trial with defined entry and activity criteria and using ASAS core outcomes to assess the efficacy of probiotic therapy in this context. The study was adequately powered to detect a significant difference in one of the primary outcome domains. Probiotic therapy did not improve disease activity, function, or quality of life in patients with SpA treated over a 12-week period. A strong placebo response was evident, with both groups demonstrating an improvement in the majority of measures over the course of the trial. A potent placebo effect has been noted in other clinical trials in SpA and may in part reflect the paucity of effective treatments, prior to the recent introduction of anti-TNF therapy ${ }^{40,41}$.

The narrow $95 \%$ confidence intervals for the majority of individual measures preclude any clinically significant benefit from the probiotic preparation. The minimum clinically important difference (MCID: the smallest change in a measure that is considered to represent clinically relevant improvement) was not achieved even at the outermost limits of the confidence intervals for the majority of outcome measures employed ${ }^{42}$. This makes the chance of a type II error (failing to observe a difference when in truth one exists) very low. When the composite ASAS20 criteria were applied, there was no evidence of a probiotic benefit, with $6 / 32(18.8 \%)$ in the probiotic group and $9 / 31(25.8 \%)$ in the placebo group achieving an ASAS20 response at the end of Personal non-commercial use only. The Journal of Rheumatology Copyright @ $\subseteq 2010$. All rights reserved. 
the 12-week intervention period $(\mathrm{p}=0.338)$. This precludes any clinically significant benefit of probiotics on an individual patient basis.

There are 4 possible principal explanations for these findings: probiotics are not an effective treatment of spondyloarthritis, the probiotic preparation trialed was not effective, a longer duration of therapy is required, or probiotic treatment should be given at an earlier stage of disease. The results of the trial may reflect a true absence of clinical effectiveness for probiotics in the treatment of SpA. In support of this explanation, the only other clinical trial addressing this question also failed to demonstrate significant benefit. Brophy, et al conducted an Internet-based trial, randomizing 147 patients with SpA to probiotic or placebo for 12 weeks $^{40}$. Limitations of their study included possible selection bias, absence of active disease as an entry criterion, and high dropout rate.

In further support for a true lack of efficacy, measures of intestinal inflammation - fecal calprotectin and the bowel symptom questionnaire (DISQ) - did not reveal any probiotic benefit. The hypothesis for a probiotic benefit in SpA is based on effects on intestinal inflammation. At Week 12, mean calprotectin concentrations were essentially unchanged in both groups, with no significant probiotic effect observed. Further, while the DISQ scores improved in both groups, again there was no probiotic benefit demonstrated. This suggests that probiotics did not have an effect on ileocolitis that was measurable by changes in calprotectin or bowel symptom score (DISQ).

There are very limited data to guide the choice of probiotic strain for clinical trials. It can be argued therefore, that an alternative probiotic preparation to the one chosen may confer benefit in SpA. The choice of probiotic strains used in our study was based as much as possible on published in vitro, animal, and clinical trials. S. salivarius K12 has exhibited antimicrobial properties and has been shown to downregulate the inflammatory response in epithelial cells by inhibiting the nuclear factor-kB pathway, and to stimulate beneficial pathways including type I and II interferon responses ${ }^{43,44,45}$. Further, other probiotic preparations, most notably VSL\#3, have incorporated $S$. salivarius strains and demonstrated an ability to prevent relapsing pouchitis in patients with ulcerative colitis ${ }^{12}$. B. lactis has also been used in combination probiotic preparations, demonstrating clinical benefit in $\mathrm{IBD}^{12,46}$. Bifidobacteria species show evidence of antibacterial activity and enhanced innate and acquired immunity in both animal and in vitro experiments ${ }^{47}$. L. acidophilus is used in the production of commercial yogurts and is a component of VSL\#3. Lactobacillus species have shown promising results in animal models of collagen-induced arthritis, with modified cellular and humoral immune responses and attenuated development of arthritis $^{48}$.

Given the chronic course of SpA and the deformities associated with longstanding disease, it could be argued that a longer duration of probiotic therapy than undertaken in our study may be needed to demonstrate benefit. Further, if probiotics exert their effects by ameliorating intestinal inflammation it might be expected that some time might elapse before improvement was evident in activity of SpA, and particularly in function. A longer duration of probiotic therapy of 24-48 weeks would have helped to address these concerns. However, since there was no measurable effect on bowel symptoms over the period of the study, it is unlikely that this was the sole reason for a lack of efficacy. Probiotic treatment has demonstrated benefit in patients with IBD over a period as short as 12 weeks, suggesting that beneficial effects of probiotic therapy are attainable in a 12-week study period ${ }^{13}$.

In our study the mean disease duration was 8.9 years with mean BASFI of 3.5. Many clinical trials in SpA have excluded patients with severe longstanding disease. Patients with greater duration of disease are more likely to have radiographic evidence of extensive fusion and ankylosis of vertebral and sacroiliiac joints. These structural changes are irreversible; however, there is evidence that treatment can still be effective at this late stage of disease and can offer substantial improvements in quality of life and disease activity ${ }^{2,49}$.

Our study demonstrates the safety of the probiotic preparation used. No significant differences between the active and placebo groups were noted in the incidence or type of adverse events. All events were rated as minor and most were self-limiting. None required cessation of the study agent. The lack of adverse events in other clinical studies for which various probiotic treatments have been investigated is consistent with our findings. Trials in IBD have reported no significant difference between probiotic and placebo groups, and large multicenter trials for childhood gastroenteritis also found no increase in side effects attributable to

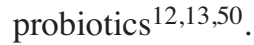

Our randomized controlled trial of a probiotic agent in the treatment of active $\mathrm{SpA}$ demonstrated no significant benefit over placebo in terms of gastrointestinal symptoms, disease activity, pain, function, or quality of life. Probiotic therapy was not associated with an increase in adverse events. Based on these findings, this particular probiotic combination cannot be recommended for the treatment of $\mathrm{SpA}$; however, future research could investigate alternative probiotic strains and a longer duration of therapy.

\section{ACKNOWLEDGMENT}

We thank Debra McNamara for her assistance with patient assessment.

\section{REFERENCES}

1. Zink A, Braun J, Listing J, Wollenhaupt J. Disability and handicap in rheumatoid arthritis and ankylosing spondylitis - results from the German rheumatological database. German Collaborative Arthritis Centers. J Rheumatol 2000;27:613-22. Personal non-commercial use only. The Journal of Rheumatology Copyright (c) 2010. All rights reserved. 
2. Wanders A, Heijde D, Landewe R, Behier JM, Calin A, Olivieri I, et al. Nonsteroidal antiinflammatory drugs reduce radiographic progression in patients with ankylosing spondylitis: a randomized clinical trial. Arthritis Rheum 2005;52:1756-65.

3. Haibel H, Brandt HC, Song IH, Brandt A, Listing J, Rudwaleit M, et al. No efficacy of subcutaneous methotrexate in active ankylosing spondylitis: a 16-week open-label trial. Ann Rheum Dis 2007;66:419-21.

4. Corkill MM, Jobanputra P, Gibson T, Macfarlane DG. A controlled trial of sulphasalazine treatment of chronic ankylosing spondylitis: failure to demonstrate a clinical effect. Br J Rheumatol 1990; 29:41-5.

5. Davis JC Jr, van der Heijde D, Braun J, Dougados M, Cush J, Clegg $\mathrm{DO}$, et al. Recombinant human tumor necrosis factor receptor (etanercept) for treating ankylosing spondylitis: a randomized, controlled trial. Arthritis Rheum 2003;48:3230-6.

6. Karimi O, Pena AS. Probiotics in arthralgia and spondyloarthropathies in patients with inflammatory bowel disease. Prospective randomized trials are necessary. Rev Esp Enferm Dig 2005;97:570-4.

7. FAO/WHO. Health and nutritional properties of probiotics in food including powder milk with live lactic acid bacteria. Geneva: World Health Organization; 2001. Available from: http://www.who.int/foodsafety/publications/fs_management/en/ probiotics.pdf

8. Reid G. Safe and efficacious probiotics: what are they? Trends Microbiol 2006;14:348-52.

9. Schultz M, Lindstrom AL. Rationale for probiotic treatment strategies in inflammatory bowel disease. Exp Rev Gastroenterol Hepatol 2008;2:337-55

10. Schultz M, Veltkamp C, Dieleman LA, Grenther WB, Wyrick PB, Tonkonogy SL, et al. Lactobacillus plantarum $299 \mathrm{~V}$ in the treatment and prevention of spontaneous colitis in interleukin-10-deficient mice. Inflamm Bowel Dis 2002;8:71-80.

11. Borruel N, Carol M, Casellas F, Antolin M, de Lara F, Espin E, et al. Increased mucosal tumour necrosis factor alpha production in Crohn's disease can be downregulated ex vivo by probiotic bacteria. Gut 2002;51:659-64.

12. Gionchetti P, Rizzello F, Helwig U, Venturi A, Lammers KM, Brigidi P, et al. Prophylaxis of pouchitis onset with probiotic therapy: a double-blind, placebo-controlled trial. Gastroenterology 2003;124:1202-9

13. Kruis W, Fric P, Pokrotnieks J, Lukas M, Fixa B, Kascak M, et al. Maintaining remission of ulcerative colitis with the probiotic Escherichia coli Nissle 1917 is as effective as with standard mesalazine. Gut 2004;53:1617-23.

14. Garcia Vilela E, De Lourdes De Abreu Ferrari M, Oswaldo Da Gama Torres H, Guerra Pinto A, Carolina Carneiro Aguirre A, Paiva Martins F, et al. Influence of Saccharomyces boulardii on the intestinal permeability of patients with Crohn's disease in remission. Scand J Gastroenterol 2008;43:842-8.

15. Timmerman HM, Koning CJ, Mulder L, Rombouts FM, Beynen AC. Monostrain, multistrain and multispecies probiotics - A comparison of functionality and efficacy. Int J Food Microbiol 2004;96:219-33.

16. Besselink MG, van Santvoort HC, Buskens E, Boermeester MA, van Goor H, Timmerman HM, et al. Probiotic prophylaxis in predicted severe acute pancreatitis: a randomised, double-blind, placebo-controlled trial. Lancet 2008;371:651-9.

17. Cannon JP, Lee TA, Bolanos JT, Danziger LH. Pathogenic relevance of Lactobacillus: a retrospective review of over 200 cases. Eur J Clin Microbiol Infect Dis 2005;24:31-40.

18. Mielants H, Veys EM, Cuvelier C, de Vos M. Ileocolonoscopic findings in seronegative spondylarthropathies. $\mathrm{Br} \mathrm{J}$ Rheumatol 1988;27 Suppl 2:95-105.
19. Rath HC, Herfarth HH, Ikeda JS, Grenther WB, Hamm TE Jr, Balish E, et al. Normal luminal bacteria, especially Bacteroides species, mediate chronic colitis, gastritis, and arthritis in HLA-B27/human beta 2 microglobulin transgenic rats. J Clin Invest 1996;98:945-53.

20. Bjarnason I, Helgason KO, Geirsson AJ, Sigthorsson G, Reynisdottir I, Gudbjartsson D, et al. Subclinical intestinal inflammation and sacroiliac changes in relatives of patients with ankylosing spondylitis. Gastroenterology 2003;125:1598-605.

21. Stebbings SM, Schultz M, Dudley-Brown S, Highton J. The severity of bowel symptoms is similar in active ankylosing spondylitis and Crohn's disease. Ann Rheum Dis 2009;68 Suppl 3:649.

22. Stebbings S, Munro K, Simon MA, Tannock G, Highton J, Harmsen $\mathrm{H}$, et al. Comparison of the faecal microflora of patients with ankylosing spondylitis and controls using molecular methods of analysis. Rheumatology 2002;41:1395-401.

23. Stebbings SM, Taylor C, Tannock GW, Baird MA, Highton J. The immune response to autologous bacteroides in ankylosing spondylitis is characterized by reduced interleukin 10 production. J Rheumatol 2009;36:797-800.

24. Vaile JH, Meddings JB, Yacyshyn BR, Russell AS, Maksymowych WP. Bowel permeability and CD45RO expression on circulating CD20+ B cells in patients with ankylosing spondylitis and their relatives. J Rheumatol 1999;26:128-35.

25. Smale S, Natt RS, Orchard TR, Russell AS, Bjarnason I. Inflammatory bowel disease and spondylarthropathy. Arthritis Rheum 2001;44:2728-36.

26. Dougados M, van der Linden S, Juhlin R, Huitfeldt B, Amor B, Calin A, et al. The European Spondylarthropathy Study Group preliminary criteria for the classification of spondylarthropathy. Arthritis Rheum 1991;34:1218-27.

27. Garrett S, Jenkinson T, Kennedy LG, Whitelock H, Gaisford P, Calin A. A new approach to defining disease status in ankylosing spondylitis: the Bath Ankylosing Spondylitis Disease Activity Index. J Rheumatol 1994;21:2286-91.

28. Calin A, Garrett S, Whitelock H, Kennedy LG, O'Hea J, Mallorie P, et al. A new approach to defining functional ability in ankylosing spondylitis: the development of the Bath Ankylosing Spondylitis Functional Index. J Rheumatol 1994;21:2281-5.

29. Heuft-Dorenbosch L, Spoorenberg A, van Tubergen A, Landewe R, van ver Tempel $\mathrm{H}$, Mielants $\mathrm{H}$, et al. Assessment of enthesitis in ankylosing spondylitis. Ann Rheum Dis 2003;62:127-32.

30. van der Heijde D, Dougados M, Davis J, Weisman MH, Maksymowych W, Braun J, et al. ASsessment in Ankylosing Spondylitis International Working Group/Spondylitis Association of America recommendations for conducting clinical trials in ankylosing spondylitis. Arthritis Rheum 2005;52:386-94.

31. Belza BL, Henke CJ, Yelin EH, Epstein WV, Gilliss CL. Correlates of fatigue in older adults with rheumatoid arthritis. Nurs Res 1993;42:93-9.

32. Turan Y, Duruoz MT, Bal S, Guvenc A, Cerrahoglu L, Gurgan A. Assessment of fatigue in patients with ankylosing spondylitis. Rheumatol Int 2007;27:847-52.

33. Doward LC, Spoorenberg A, Cook SA, Whalley D, Helliwell PS, Kay LJ, et al. Development of the ASQoL: a quality of life instrument specific to ankylosing spondylitis. Ann Rheum Dis 2003;62:20-6.

34. Jenkinson TR, Mallorie PA, Whitelock HC, Kennedy LG, Garrett SL, Calin A. Defining spinal mobility in ankylosing spondylitis (AS). The Bath AS Metrology Index. J Rheumatol 1994;21:1694-8.

35. Sutherland AD, Gearry RB, Frizelle FA. Review of fecal biomarkers in inflammatory bowel disease. Dis Colon Rectum 2008;51:1283-91.

36. Thjodleifsson B, Sigthorsson G, Cariglia N, Reynisdottir I, 
Gudbjartsson DF, Kristjansson K, et al. Subclinical intestinal inflammation: an inherited abnormality in Crohn's disease relatives? Gastroenterology 2003;124:1728-37.

37. Kronborg O, Ugstad M, Fuglerud P, Johne B, Hardcastle J, Scholefield JH, et al. Faecal calprotectin levels in a high risk population for colorectal neoplasia. Gut 2000;46:795-800.

38. Tibble J, Teahon K, Thjodleifsson B, Roseth A, Sigthorsson G, Bridger $\mathrm{S}$, et al. A simple method for assessing intestinal inflammation in Crohn's disease. Gut 2000;47:506-13.

39. Anderson JJ, Baron G, van der Heijde D, Felson DT, Dougados M. Ankylosing Spondylitis Assessment Group preliminary definition of short-term improvement in ankylosing spondylitis. Arthritis Rheum 2001;44:1876-86.

40. Brophy S, Burrows CL, Brooks C, Gravenor MB, Siebert S, Allen SJ. Internet-based randomised controlled trials for the evaluation of complementary and alternative medicines: probiotics in spondyloarthropathy. BMC Musculoskelet Disord 2008;9:4.

41. Braun J, Zochling J, Baraliakos X, Alten R, Burmester G, Grasedyck K, et al. Efficacy of sulfasalazine in patients with inflammatory back pain due to undifferentiated spondyloarthritis and early ankylosing spondylitis: a multicentre randomised controlled trial. Ann Rheum Dis 2006;65:1147-53.

42. Tubach F, Ravaud P, Beaton D, Boers M, Bombardier C, Felson DT, et al. Minimal clinically important improvement and patient acceptable symptom state for subjective outcome measures in rheumatic disorders. J Rheumatol 2007;34:1188-93.

43. Ross KF, Ronson CW, Tagg JR. Isolation and characterization of the lantibiotic salivaricin A and its structural gene salA from Streptococcus salivarius 20P3. Appl Environ Microbiol 1993;59:2014-21.
44. Upton M, Tagg JR, Wescombe P, Jenkinson HF. Intra- and interspecies signaling between Streptococcus salivarius and Streptococcus pyogenes mediated by SalA and SalA1 lantibiotic peptides. J Bacteriol 2001;183:3931-8.

45. Cosseau C, Devine DA, Dullaghan E, Gardy JL, Chikatamarla A, Gellatly S, et al. The commensal Streptococcus salivarius K12 downregulates the innate immune responses of human epithelial cells and promotes host-microbe homeostasis. Infect Immun 2008;76:4163-75.

46. Gionchetti P, Rizzello F, Venturi A, Brigidi P, Matteuzzi D, Bazzocchi G, et al. Oral bacteriotherapy as maintenance treatment in patients with chronic pouchitis: a double-blind, placebo-controlled trial. Gastroenterology 2000;119:305-9.

47. Roopashri AN, Varadaraj MC. Molecular characterization of native isolates of lactic acid bacteria, bifidobacteria and yeasts for beneficial attributes. Appl Microbiol Biotechnol 2009;83:1115-26.

48. Kato I, Endo-Tanaka K, Yokokura T. Suppressive effects of the oral administration of Lactobacillus casei on type II collagen-induced arthritis in DBA/1 mice. Life Sci 1998;63:635-44.

49. Rudwaleit M, Olivieri I, Boki KA, Griep EN, Jarvinen P, Wong RL, et al. Adalimumab is effective and well tolerated in treating patients with ankylosing spondylitis who have advanced spinal fusion. Rheumatology 2009;48:551-7.

50. Guandalini S, Pensabene L, Zikri MA, Dias JA, Casali LG, Hoekstra H, et al. Lactobacillus GG administered in oral rehydration solution to children with acute diarrhea: a multicenter European trial. J Pediatr Gastroenterol Nutr 2000;30:54-60. 